\title{
Controversias en la transición del libro de texto en papel y electrónico a los contenidos digitales
}

\section{Controversies in the transition from paper and electronic textbooks to digital content}

\author{
Ángel San Martín Alonso \\ Universitat de València. Valencia (España) \\ asanmart@uv.es \\ José Peirats Chacón \\ Universitat de València. Valencia (España) \\ jopeicha@uv.es
}

\begin{abstract}
Resumen
Cabe pensar, dada la magnitud económica y cultural que representa el libro en nuestra sociedad, ya sea en soporte papel como electrónico, que los dos van a convivir largo tiempo. Los libros de texto, en consecuencia, correrán una suerte muy semejante. El cambio actual lo focalizamos en la transformación de los libros de texto en contenidos digitales con distintos formatos y vías de acceso. De este proceso estudiamos las controversias que suscitan estos cambios, en tanto que son reflejo del grado de asimilación por parte de la ciudadanía de las referidas innovaciones tecnológicas. Mediante estrategias etnográficas, nos acercamos a distintos agentes escolares para tratar de comprender inductivamente cómo están acogiendo tales innovaciones. Los centros estudiados son de varias comunidades autónomas, tomando como muestra los dos últimos cursos de primaria. Se observa entre los padres un dispar posicionamiento ante la incorporación de los nuevos medios, unas veces por los costes, otras porque reconocen no tener tantas habilidades como los chicos y chicas, aunque casi todos comparten el que es necesario educarlos en el uso de estas tecnologías porque es lo que necesitarán cuando sean adultos.
\end{abstract}

\section{Palabras clave}

Libro de texto, digital, modelo didáctico, materiales curriculares.

\begin{abstract}
It is suggested that, given the economic and cultural scale that the book represents in our society, the layout of the paper and digital version will live together for a long time. Therefore, textbooks will suffer a very similar fate. The current change is focused on the transformation of textbooks in digital content with different formats and access routes. Through this process, we are studying the disputes that these changes cause, whereas they reflex the level of assimilation of the technological innovations on the part of citizens. By means of ethnographic strategies, we try to understand inductively how different educational agents are accepting such innovations. The centres that we have studied belong to various autonomous communities and data has been analysed for the last two years of primary school. In light of new media, we observe that parents have taken disparate positions among them: for the costs or parents who acknowledge that they have not as many skills as children. However, almost everyone agrees that it is necessary to educate in the use of these technologies because they will need it into adulthood.
\end{abstract}

Keywords

Textbook, digital book, didactic model, curricular materials. 
Más que cualquier otra invención particular, la escritura ha transformado la conciencia humana. (Ong, 1987).

\section{Introducción}

Al observar los procesos de enseñanza y aprendizaje se advierte de inmediato que siempre han estado y están, estrechamente unidos con el manejo de un amplio espectro de artefactos. En el conjunto de esta panoplia, el libro, sea o no de texto, es uno más entre tantos otros. ¿Durante cuánto tiempo más va a seguir estando presente el libro? Por otra parte, si admitimos que el libro es un artefacto tecnológico, entonces su evolución dependerá, entre otros factores, de la innovación de la tecnología. Ahora bien, ¿hasta qué punto el sector tecnológico está interesado en desarrollar innovaciones en el sector del libro en cuanto tal?

Es probable que ya no nos acordemos que hace unos pocos años se hablaba de la digitalización de bibliotecas enteras por parte de una empresa tecnológica como Google (Vercelli, Becerra \& Bidinost, 2016). En el último tercio de este 2017, la citada multinacional está de actualidad no sólo por las sanciones de la UE o por la presentación que su CEO ha hecho del novedoso smartphone. Lo está porque, para competir con Apple, presentó un pequeño artefacto llamado Google Pixel Buds. Se trata de un auricular que, al decir de la publicidad de la compañía, recreada con grandes titulares por la prensa, se anunciaba: "Hablar cuarenta idiomas: un sueño hecho realidad..." (La Vanguardia, 13/10/2017). ¿Qué hacemos ahora con los libros de idiomas, con los blogs, con los objetos de aprendizaje, con los MOOC y de paso también con la definición de competencias?

La noticia promocional precedente nos da la medida de cómo evolucionan las aplicaciones tecnológicas y las cautelas a considerar en este trabajo. Por tanto, no nos detendremos en pronosticar el futuro del libro de texto, sea en papel o digital. Nos centramos en las controversias provocadas por la transición de una a otra generación de tecnología, por cuanto no se limitan al libro sino a desarrollar productos alternativos como los auriculares referidos más arriba o lo que la industria cultural denomina "contenido digital". Lo sustantivo de esta innovación no es tanto facilitar el acceso a unos contenidos valiosos culturalmente como transformar las relaciones de producción, distribución y acceso al conocimiento ensayando nuevas vías que aseguren su monetización. Y este es el contexto en el que planteamos algunas de las controversias que rodean a la transición de un soporte a otro, y cómo debería ser su recepción en las aulas o entornos de enseñanza y aprendizaje. 


\section{Consideraciones preliminares}

\section{1 ¿Tiene futuro el libro de texto?}

El libro de texto o manual escolar, pese a lo controvertido del formato y con frecuencia también del contenido, ahí tenemos la polémica en EEUU y en España por asociar homosexualidad a patología, discriminación de género o la presencia de signos identitarios en los libros de texto. Los estudios y trabajos sobre el libro de texto y su función en las prácticas de enseñanza vienen de muy largo y desde perspectivas muy diversas. Sólo a modo indicativo: Escudero (1983), Apple (1989), Valls (1998), Martínez Bonafé (2002), Choppin (2002), Escolano (2009), Rodríguez, Bruillard \& Horsley, (Coords.) (2015), Proyecto MANES que en su web referencia investigaciones y publicaciones sobre manuales y libros de texto.

En todo caso, el libro de texto es heredero del Libro, así, con mayúscula. Lo cual significa, entre otras cosas, que van a correr suertes muy semejantes. Tras la revisión de numerosas aportaciones de especialistas, Celaya (2016, p. 3) concluye que la actual decaída del libro en papel, será aprovechada por algunas editoriales para "implementar nuevos modelos de negocio, algoritmos de recomendaciones basados en Big Data así como estrategias de distribución globales con precios y servicios competitivos". Pese a estos drásticos cambios en la cadena de producción, distribución y lectura del libro, todo indica que el libro clásico va a seguir conviviendo con los distintos formatos que proporcione la innovación tecnológica.

Si damos una mirada a las grandes cifras del mercado interior del libro, nos encontramos que en 2016 se editaron 81.496 títulos generando una producción de 224.054 millones de ejemplares, de los cuales se vendieron el 70,1\%. Las ventas supusieron 2.317,20 millones de euros, un 2,7\% más que en el ejercicio de 2015 . Y como resultado de las sucesivas concentraciones de las editoriales, en el 2016 dos grupos (Planeta y Penguin Randon House) coparon el 23,2\% de la cuota del mercado interior del libro (FGEE, 2017: pp. 113-115). Y según las mismas fuentes, para el mismo período, el $36,9 \%$ de esa producción corresponde al "Texto no universitario" con una facturación de 856,04 millones de euros, un 3,1\% de incremento respecto al año anterior. A estas cifras, en buena lógica, habría que añadirles los 103,01 millones de euros facturados en el capítulo de libros científico-técnicos y universitarios, con un incremento del 8\% respecto al ejercicio del 2015 (según un estudio del CSIC coordinado por Giménez, 2017, el 20\% de la producción es "edición académica"). Respecto al libro en formato electrónico, la facturación en 2016 fue de 117 millones de euros, lo que supone un leve crecimiento respecto al ejercicio anterior y una cuota de mercado del $5 \%$.

A partir de estas grandes cifras, es difícil imaginar un final inminente del artefacto libro, ya sea en soporte papel o en su versión digital. De manera que lo más razonable es pensar que convivirán unos recursos tecnológicos con otros, aunque según la época unos dominarán sobre otros. Conviene, a este respecto, recordar la reflexión de Goody y Watt (1996, p.77) cuando mantienen que "en nuestra civilización, la escritura es claramente una adición, y no una alternativa, a la transmisión oral". Otro tanto, pues, cabe afirmar con las novedades en torno al libro respecto a lo que nos deparen las

Controversias en la transición del libro de texto en papel y electrónico a los contenidos digitales. Ángel San Martín Alonso y José Peirats Chacón. 
innovaciones tecnológicas para acceder a los contenidos de aprendizaje. Una muestra de ello son las plataformas que las editoriales convencionales ponen en marcha para facilitar el acceso a contenidos digitales, unos vinculados a la compra del libro de texto y otros de acceso libre. La plataforma AMIGO es el acrónimo de un proyecto, con financiación europea y liderado por la editorial Edebé, orientado a crear contenidos de ciencias, matemáticas y tecnología con el que seguir apostando por "la innovación educativa y el desarrollo de proyectos que contribuyan a la mejora de contenidos, herramientas..." (Redacción Boletín Salesiano, 2017).

Iniciativas como la citada confirman que el libro de texto convencional seguirá conviviendo con las alternativas tecnológicas. Y será así no sólo por el enorme peso que tiene su facturación en la industria del libro, hay algunos otros elementos que son tanto o más importantes que el económico. Recordemos que el Real Decreto 1744/1998, de 31 de julio, todavía mantenía la supervisión administrativa de los libros y materiales curriculares, y hasta la Ley Orgánica 8/2013, de 9 de diciembre, no se recoge "el préstamo gratuito de libros de texto y otros materiales...". Como concluye Varela Mallou (2008, p. 109), el libro de texto cumple una función vertebradora en las aulas, pues presentan unos contenidos de calidad, contrastables, bien estructurados, ajustados al proyecto curricular de centro y además compendiados en un documento. Conseguir todo esto exige un conocimiento muy especializado que sólo manejan las editoriales, lo cual queda alejado del modelo de negocio que propician hoy las tecnologías.

En el informe antes citado se advierte que, dado lo que ha pasado en otros sectores como la música, el cine o la televisión, la industria del libro debe buscar sin demora respuestas innovadoras a las demandas de las aulas. Pues ante el retraso de estas iniciativas se constata la creciente presencia de nuevos actores (profesorado, empresas, ONGs, instituciones, etc.), ofreciendo productos y servicios relacionados con la generación de contenidos educativos digitales. Y este es el nudo gordiano del tema que tratamos aquí: el problema no es el libro de texto, ni siquiera de la pluralidad de materiales curriculares en soporte digital, la cuestión de fondo es el acceso a los contenidos de aprendizaje y el modelo de negocio en el que sustentarlo. No descubrimos nada con esto, es lo que los responsables de las editoriales que hemos entrevistado nos han dicho con mayor o menor claridad, pues tienen a sus creativos ensayando respuestas al desafío tecnológico, pero sin que disminuyan los retornos económicos. Circunstancia de la que surgen los argumentos sobre los que se sustentan las controversias latentes en la transición de lo que podríamos formular como el paso de los libros de texto a los "contenidos digitales".

No se nos escapa que, pese al uso generalizado de esta expresión, no está exenta de múltiples servidumbres semánticas. Tal como señala Bustamante (2011a), se trata de un concepto acuñado por la industria del entretenimiento y el ocio en analógico con el que nombrar y acotar un tipo de producto sometido únicamente a la lógica del mercado. De esta manera se desprende de toda connotación cultural e incluso formativa, para ser protegido por la propiedad intelectual que generaría los retornos económicos. De hecho, como resalta el autor citado, en nuestro contexto son las operadoras de telecos y la patronal de la electrónica, las que han incorporado este concepto en sus informes anuales y que luego se citan profusamente (ONTSI depende del Ministerio de Energía,

Controversias en la transición del libro de texto en papel y electrónico a los contenidos digitales. Ángel San Martín Alonso y José Peirats Chacón. 
Turismo y Agenda Digital, aunque el primer informe sobre el particular lo patrocinó la AMETIC, asociación de la patronal de la electrónica).

Según la Ley 3/2014, de 27 de marzo, con la que se transpone al ordenamiento español la Directiva 2011/83/UE, en su Art. 59bis, se establece la siguiente definición: “i) 'contenido digital': los datos producidos y suministrados en formato digital". Más genéricamente se podría afirmar que, "contenido digital", es cualquier elemento expresivo, registrado en bits y susceptible de ser difundido a través de alguno de los canales de telecomunicaciones. Este elemento puede ser un grafismo, una canción, una fotografía, la visita virtual a un museo o un videojuego; lo sustantivo es el formato electrónico que se registra, propiedad de éste y las oportunidades de difusión en distintos soportes. Entre estas características no está la calidad o valía de lo expresado que pasa a un segundo plano, lo verdaderamente importante es el "modelo de negocio" que permita rentabilizar un intangible como es el contenido digital.

A partir de numerosas evidencias mantenemos que se está produciendo el paso del libro a los contenidos digitales, basándonos, entre otros datos, en que la media de digitalización del resto de ámbitos de los contenidos digitales en 2015 es del 57,8\%, mientras que en el segmento del libro y demás publicaciones es del 12\% (ONTSI, 2016). Si tenemos en cuenta que los libros y demás publicaciones sólo representan un $7,7 \%$ del total de facturación, suponemos que la evolución se experimentará incrementando la oferta de contenidos digitalizados provenientes de los distintos ámbitos culturales, también de los educativos. Es decir, el cambio no vendrá acelerando la digitalización del formato libro (e-book, pdf, etc.), sino ofertando contenidos en diferentes formatos, procedencias y muchos de autoedición. De hecho, ahí está ya, aunque carezcamos de datos fiables, el acceso a vídeos tutoriales de contenidos curriculares en YouTube, repositorios de piezas elaboradas por docentes, proyectos patrocinados por empresas que generan blogs y materiales propios o, las múltiples aplicaciones para desarrollar contenidos escolares con el formato de videojuegos o de concursos. El producto se ofrece como gratuito porque lo financian terceros a cambio de cederles la comercialización de la información que se desprende de los accesos al producto digital.

\section{2 ¿Por qué plantear controversias en este terreno?}

Recurrimos a las controversias porque consideramos que hay tantas dudas como certezas en la transición del libro de texto a los distintos formatos de contenido digital, múltiples direcciones. Tomamos las controversias como recurso metodológico para avanzar en la comprensión del fenómeno que nos ocupa. El filósofo de la ciencia Nudler (2009), habla de "espacio controversial" para referirse a la asunción de una serie de principios en torno a un determinado problema. La confrontación de los principios suscita, de inmediato, disensos que se han de ir resolviendo mediante la investigación para clarificar los extremos en disputa. Los disensos pueden surgir tanto en el plano teórico, metodológico, ideológico o ético. Cuando las controversias se desarrollan con rigor, entonces pueden salir a la superficie "supuestos, convenciones o acuerdos tácitos que, en períodos de consenso, rara vez se hacen explícitos" (Aibar, 2002, p. 107). Pero la función no es sólo epistémica, también la tienen social y política, pues en última instancia supone implicar a la ciudadanía participando en asuntos relativos a la ciencia y

Controversias en la transición del libro de texto en papel y electrónico a los contenidos digitales. Ángel San Martín Alonso y José Peirats Chacón. 
la tecnología que son cada vez más relevantes para nuestras vidas (Martín Gordillo, 2006).

Los autores que apuestan por esta perspectiva asumen que los avances en la ciencia y la tecnología deben ser valorados también por la ciudadanía, pues las innovaciones tecnológicas no son valiosas por sí mismas. Y llegados a este punto, ¿no convendría que docentes, familias e incluso los estudiantes de las etapas escolares más elevadas, se pronunciaran sobre el paso del libro de texto convencional al electrónico y de éstos a los contenidos digitales? ¿Quién y cómo se va a supervisar el acceso a éstos y acreditar los aprendizajes? La innovación tecnológica ya ha rebasado a las populares TIC para entrar en el estadio de la "biocibernética" (Mitchell, 2017), que ofrece auriculares o aplicaciones para allanar el aprendizaje de todo tipo de conocimiento. Convendría, por tanto, articular un debate reposado sobre el valor en las aulas de propuestas de "innovación" como flipped classroom, learning analytic, deep learning, etc.

A fin de ordenar el debate sobre la disputa entre los libros de texto y los contenidos digitales, retomamos un trabajo previo en el que, a propósito de los materiales curriculares, se identificaban tres dimensiones implicadas en el proceso de incorporación de las diferentes tecnologías al ámbito escolar. Se trataría de la dimensión tecnológica, la pedagógica y la comercial de la industria editorial (Peirats, Gallardo, San Martín \& Cortés, 2015). En un momento posterior, añadimos una cuarta que es la dimensión institucional, la cual se interesa por los agentes sociales y económicos que, de un modo u otro, intervienen regulando la cadena de valor de las tecnologías. Se trata, por lo demás, de cuatro dimensiones sobre las que se ha sustentado el artefacto libro y que ahora las ponen en cuestión los nuevos dispositivos que ni siquiera requieren la lectura.

\section{Marco metodológico}

El objetivo principal de este trabajo es analizar algunas de las controversias que suscita la transición de los libros de textos clásicos y electrónicos a los contenidos digitales. Para alcanzar este propósito nos situamos en la tradición de los estudios de ciencia, tecnología y sociedad (ECTS), los cuales se apoyan en enfoques metodológicos eminentemente etnográficos y en contextos naturalistas. En este trabajo, tal como ya se ha apuntado más arriba, adoptamos una perspectiva de metaevaluación pues retomamos los datos y reflexiones de un proyecto de investigación que se interesa por los cambios impulsados por la presencia en las aulas de los materiales digitales.

Los materiales de campo proceden de la segunda fase del proyecto de investigación citado en la nota 1, en la que nos ocupamos de las opiniones y percepciones de los distintos agentes escolares. La selección de los sujetos informantes responde a un criterio de oportunidad además que respondieran a los objetivos, atendiendo también a la valía de sus aportaciones (Stake, 1998). Los sujetos pertenecen a tres comunidades autónomas diferentes y procuramos mantener equilibradas variables como las de género, titularidad del centro, condiciones socioeconómicas y según el nivel de saturación tecnológica de los centros. Los informantes provienen de cinco colectivos diferentes: docentes, estudiantes de $5^{\circ}$ y $6^{\text {a }}$ de Primaria, las familias con hijos en esta 
edad y responsables de editoriales con libros digitales, además de algún representante de la administración autonómica.

Todas las entrevistas, tras la gestión y firma de los documentos de confidencialidad correspondientes, fueron grabadas únicamente en audio y luego transcritas siguiendo una serie de normas que se plasmaron en un protocolo a fin de unificar criterios de procedimiento. Las entrevistas y grupos de discusión se realizaban conforme a un guion y debían durar entre 45 y 60 minutos. Las transcripciones las analizaremos en dos fases, la segunda será con el programa Atlas.ti, si bien aquí nos interesa la primera porque es de la que nos ocuparemos. A partir de las cuatro dimensiones establecidas, siguiendo el modelo de codificación de la teoría fundamentada (Strauss \& Corbien, 1998), revisamos los textos para encontrar los segmentos de texto coincidentes con las dimensiones preestablecida y que reflejaran la disparidad de puntos de vista o los disensos. Con los resultados de este procedimiento inductivo, tratamos de reconstruir las controversias asociadas con cada una de las dimensiones y que exponemos a continuación.

\section{Espacios controversiales en la transición del libro de texto}

\subsection{La innovación tecnológica}

Durante estas últimas décadas, la evolución de la innovación tecnológica es tan rápida y espectacular que no se repara demasiado en su significado e implicaciones. Tal sería el caso, por ejemplo, del adjetivo "digital" utilizado para describir un determinado producto o servicio; sin embargo, más bien se trata de un sustantivo con el que nombrar a la tecnología más potente de nuestros días y verdadero motor de cambios sustantivos en nuestro entorno. Cuestión sobre la que nos resulta especialmente significativa la disquisición que hace Bustamante (2011b), al calificar toda esta tendencia de tecnologista, por cuanto confunde el contenido con el continente. En su criterio, lo digital alude a la tecnología de almacenamiento y transmisión, lo cual es algo muy distinto a los elementos simbólicos que transmiten unos u otros contenidos. Digitalizar un sonido, por ejemplo, es aplicar una tecnología que lo transforma en un algoritmo que rige el registro y la reproducción de dicho sonido.

Para hacernos cargo del impacto de esta nueva tecnología, Carreras (2017) mantiene que la entrada de la tecnología digital en el mundo de la música está provocando toda una transformación cultural, pues introduce cambios radicales tanto en la producción como en la distribución y consumo de la misma. Los aficionados de la música ya no se conforman con ser únicamente consumidores, quieren también participar de alguna manera en la gestión de su relación con la música. ¿Sucederá algo parecido en el ámbito de la educación institucional?

En cierto modo eso ya está sucediendo, el alumnado lleva a las aulas sus habilidades y aprendizajes adquiridos a través del manejo temprano de la tecnología digital. Un profesor de primaria nos decía:

En los años que llevo de profesión no sé ya cuántas modas han pasado, desde aquellos vídeos a los móviles inteligentes que hoy tienen la mayoría de nuestros alumnos y que la coordinadora de TIC trata de enseñarles a usar con

Controversias en la transición del libro de texto en papel y electrónico a los contenidos digitales. Ángel San Martín Alonso y José Peirats Chacón. 
algo de criterio. A veces me pregunto si hacemos bien insistiendo aquí con tanta tecnología, ¿por qué no les enseñamos a manejar y a disfrutar de un libro? (EP4).

Aunque el formato libro de texto está absolutamente consolidado tecnológica y culturalmente, es obvio que aparecen nuevos artefactos que cambian el modo de acceso al texto. Pero el texto alfabético, ya sea en papel o electrónico, tiene un patrón de presentación y de acceso o lectura que forma parte de nuestra cultura. Lo que ha conseguido la innovación tecnológica es quebrar ese patrón, poniendo al alcance de los ciudadanos nuevos artefactos cuyo "texto" es radicalmente distinto al del libro. El denominado contenido digital propone una relación diferente con los significados, mucho más lúdicos, fragmentados y cambiantes, justo el tipo de relación que fomenta el actual consumo del ocio y el entretenimiento, mucho más icónico que alfabético. Por tanto, ¿no convendría detenerse a pensar si el tratamiento analógico del texto tiene aún algún valor formativo y cultural respecto al digital?

\subsection{Mercantilización del acceso}

El libro como artefacto tecnológico y la lectura en tanto que práctica cultural, son componentes sustantivos de nuestro canon cultural. El libro, en cualquiera de sus formatos, como la lectura tampoco escapan a la "égida del capital" (Schiller, 2010). En la fase actual del capitalismo, impone tales condiciones a la producción y difusión del libro que sólo las grandes empresas pueden competir en el mercado. Las facilidades que hoy proporcionan las tecnologías permitían albergar la esperanza de democratizar la difusión y acceso a las obras, pero la realidad se aleja un poco de ello. Los metadatos que deben acompañar a la publicación de un libro, en papel o digital, para poderlo promocionar en las diferentes redes y luego operar con los Big Data que los usuarios van generando, encarece tanto la edición que fomenta la concentración en empresas muy poderosas, pero también muy pocas (Millán, 2015).

No obstante, del libro de texto se ocupan principalmente las editoriales pequeñas y medianas pero que, como apuntamos más arriba, la facturación representa más de un tercio del total del sector. Circunstancia que se convierte en factor crítico a la hora de gestionar la mayor o menor presencia de los libros de texto. Un alto responsable de una administración educativa autonómica nos decía:

Nosotros le podríamos decir a una editora cualquiera, mire háganos en digital todos los libros de un curso o una etapa. Nosotros asumimos el pago de lo que suponga y de esta manera las familias tendrían gratis los libros. Seguro que ninguna editorial se negaría a esto... Pero sí se negaría si yo le dijera que, a cambio, nos deberían pasar el código fuente de los libros durante cuatro años para poderlos adecuar en los centros. Ninguna editorial aceptaría esto, porque entonces les estropeamos el negocio (EA).

Si los costes de producción son cada vez más elevados, también lo serán los precios de venta al público. Y para que estos retornos se produzcan, aparecen diferentes instrumentos para proteger la propiedad intelectual y económica en la distribución de los libros. Nos referimos a las diferentes formas del copyright, frente al copyleft, además de las sociedades gestoras de derechos (controvertido Real Decreto-Ley 
12/2017, de 3 de julio, sobre la compensación de copias). Valdría decir que se dispone de los medios tecnológicos para producir contenidos casi a nivel profesional; sin embargo, las dificultades también son numerosas, especialmente con los derechos de lo ya creado. La responsable comercial de una editorial importante nos decía:

De vez en cuando nuestro personal revisa los materiales que hace el profesorado y luego cuelga en su blog o en la web del centro. Y es increíble, siempre encontramos contenidos nuestros, a veces sin cambiar nada $\mathrm{y}$, por supuesto, sin citarnos. ¡Esto no puede ser! Nosotros invertimos mucho dinero en puestos de trabajo para crear los libros y demás materiales para las aulas, por eso no me parece ético que se apropien de nuestro trabajo tan descaradamente (EE).

A tenor de los datos que circulan en diferentes informes, no parece que estas estrategias disuadan de subvertir el orden económico de los derechos de autor. Según el Observatorio de la piratería, nos encontramos que casi el $90 \%$ del consumo cultural online es ilegal, y consumido mayoritariamente por jóvenes (Palao y Jiménez, 2015). Las dos principales razones que exponen sobre este comportamiento son: se trata de productos "muy caros" y la "rapidez de acceso". De este monto total de pirateo, sólo el $3 \%$ corresponde a los libros (no se incluyen los escolares), y principalmente a los libros digitales, pese a que éstos representan una muy pequeña parte del total de la industria del libro. Son más de 100 millones de euros de pérdidas en 2015 ocasionadas a esta industria, lo que representa un $12 \%$ de incremento respecto al año anterior. Pero este fraude lo que pone de manifiesto según muchos analistas es que en el sector del libro se ha mantenido, no así en otros sectores culturales, el verticalismo entre producción y usuarios. Sin embargo, la accesibilidad de las tecnologías fomenta la autoedición, la producción de contenidos en distintos formatos, la fragmentación y la diversificación de la oferta entre múltiples agentes editoriales (Anta, 2017).

Es evidente que, tanto los libros como todos los demás contenidos culturales, experimentan la piratería en mayor o menor grado. Ahora bien, mientras el sector del libro está hiperregulado (adviértase que la Ley 10/2007, de 22 de junio, excluye del precio fijo al libro de texto), el de los contenidos digitales se regiría por las reglas del mercado y como mucho la propiedad intelectual de la creación. Y esta circunstancia obligaría a buscar los retornos económicos mediante estrategias de negocio más acordes con el digitalismo, como sería recibir publicidad, acceso a datos personales o pagos por cuota de acceso, etc. Algunos especialistas mantienen, metafóricamente, que no es lo mismo comercializar una botella de agua (un libro) que el flujo de agua de una tubería (acceso a contenidos por la red). Otros expertos hablan directamente de la "netflixización" de la cultura, aplicando criterios semejantes a la difusión del libro (Vázquez \& Celaya, 2017). Ahora bien, ¿es razonable que los agentes económicos incrementen aún más su posicionamiento en los espacios de escolaridad obligatoria sin un tangible como el libro para supervisar la difusión de contenidos?

\subsection{Empoderamiento del alumnado}

En cuanto a la tradición y hábitos culturales asociados al artefacto libro, bien se puede hablar de la "institución libro" que afecta tanto a la edición como a la escritura y a la lectura, pero también a los espacios físicos que los acogen. El diseño de los edificios

Controversias en la transición del libro de texto en papel y electrónico a los contenidos digitales. Ángel San Martín Alonso y José Peirats Chacón. 
escolares (forma rectangular de las aulas, iluminación por un lateral, unidireccionalidad de las miradas, etc.), en muy buena medida, responden a las exigencias de uso de los manuales escolares llenos de ilustraciones y textos. Si esto es así, en mayor medida lo será el que las prácticas didácticas en las aulas se conciben y desarrollan en función del artefacto libro. Todo ello configura unos hábitos de trabajo escolar, de lectura, escritura y de representación del conocimiento que no es fácil desmontar, porque no depende únicamente del artefacto libro. Una madre argumentaba:

El curso pasado estaba más preocupada por la niña, pero este es el segundo año de trabajo con la tablet y veo que va fenomenal, tiene mucha autonomía y también la profesora está muy encima. No sé si estudia mucho o no, pero confío plenamente en la maestra porque mi hija cada día se pone con sus cosas y me sorprende lo mucho que avanza (EFCS2).

A la quiebra de muchas de estas rutinas y certezas es lo que podría calificarse como la desinstitucionalización del libro. Tendencia que viene de lejos, pues la hegemonía del libro de texto en las aulas se ha intentado mitigar proponiendo aprovechar el potencial pedagógico de los medios clásicos de comunicación, luego los llamados materiales curriculares, los ordenadores, los objetos de aprendizaje, las plataformas de e-learning y ahora por los contenidos digitales. Y éstos sí representan un desafío importante al dominio de los libros de texto. La producción, distribución y acceso a estos contenidos se asocia con profundos cambios en las condiciones de trabajo, tanto del profesorado como del alumnado, y no es únicamente porque sean más entretenidos o más libres y creativos, es que modifica la relación de los usuarios con el conocimiento, con el profesorado y, por ende, con los controles que puedan establecerse. Una profesora de primaria que hace un uso intensivo de tecnologías señalaba:

Estos críos saben más que nosotros a la hora de manejar ordenadores, móviles, videojuegos y todo eso. Van muy por delante. Otra cosa muy distinta es cómo los utilizan... Les acabas de poner la tablet en su mano y nada más darte la vuelta, sin haber dicho nada, ya la han encendido para entrar en alguna aplicación... y si te descuidas hasta entran en páginas no aptas para ellos (EP4).

Como ya hemos mencionado más arriba, el libro es un sector muy regulado y el libro de texto mucho más (Puelles Benítez, 2007). De hecho, el Real Decreto 1744/1998, de 31 de julio, en el apartado 2 del artículo segundo, dispone que se "entiende por libro de texto el material impreso, de carácter duradero y autosuficiente, destinado a ser utilizado por los alumnos y que desarrolla, (...), los contenidos establecidos por la normativa académica vigente...". Frente a este modelo verticalista, la oferta de los contenidos digitales se basa en el principio contrario, los usuarios los eligen y llegado el caso hasta los producen. El principio es el empoderamiento de los usuarios; de hecho, los estudiantes manifiestan en las entrevistas su clara preferencia por los dispositivos digitales en detrimento de los libros. En una entrevista de grupo con estudiantes de sexto de un centro público comentaban:

A.- Yo prefiero la tablet porque te permite hacer los trabajos como tú quieres, aunque a veces cuando estás con eso te pierdes las explicaciones del profesor. (Risas) 
B.- Yo prefiero el ordenador porque es más fácil comunicarte... Si tienes alguna dificultad con las tareas le pones un correo al profesor y te contesta con la respuesta. Es como más personal.

A.- El problema es que, si nos ponemos todos a mandar correos, el ordenador se cuelga... (Risas), (GDA).

La preeminencia de lo visual en el nuevo orden epistémico es muy llamativa. Antes aludimos al entorno de aprendizaje AMIGO y en la web de uno de los centros, en los que se experimenta bajo el titular "El aula del futuro en nuestro centro", hay un párrafo de tres líneas y un vídeo de dos minutos, además de los enlaces a los medios de comunicación que han hablado de su experiencia (véase http://agora.xtec.cat/escolamartamata-viladecans/).

La progresiva generalización de estas prácticas invita a plantearse hasta qué punto el patrón cultural del libro es un lastre cultural frente a lo avanzado del contenido digital. Tras el reclamo del empoderamiento está la lógica neoliberal de que docentes y discentes se "hagan a sí mismos" buscando en el escaparate de los contenidos digitales. Es cuestionable el que se mantenga la supervisión administrativa de los libros de texto, pero no deja de ser también un garante de la igualdad de oportunidades en las aulas. El que la elección de los libros de texto y demás materiales curriculares corresponda a "los órganos de coordinación didáctica de los centros..." (Disposición adicional $4^{\mathrm{a}}$ de la Ley Orgánica 2/2006, de 3 de mayo), no deja de ser un ejercicio de colegialidad en una decisión fundamental en la educación. Frente a esta lógica se impone la que favorece el acceso directo, por ejemplo, a un vídeo tutorial de enseñanza de la división disponible en YouTube (en el canal Unicoos se pueden ver los vídeos del popular y reconocido profesor David Calle: https://www.unicoos.com/). Lo importante no es tanto su valía académica como que resulte atractivo para que tenga muchos accesos, criterio que sí podría generar alguna remuneración.

\subsection{Reestructuración didáctica}

El libro de literatura o de texto, sea en papel o electrónico, soporta un relato con un formato muy característico y plenamente arraigado en nuestra cultura. Este formato está presente en nuestro pensamiento, en la manera de expresarnos, en cómo contamos historias, etc. Un libro de texto en papel, en formato ePUB, MOBI o en PDF enriquecido, no deja de tener una estructura narrativa muy semejante, cuerpo de texto, letras dispuestas en líneas más o menos largas, sangrados, tipos y tamaños de letras, ilustraciones, etc. Las tecnologías digitales de nuestros días permiten dar un paso más para superar incluso el formato narrativo del libro. En palabras de Chartier (2001, p. 76), la textualidad electrónica cuestiona la idea misma de libro, entre otros motivos porque propone una lógica ya no "lineal y deductiva, sino abierta, expansiva y relacional”. Por tanto, ¿uno y otro fomentan modelos epistemológicos diferentes? ¿Qué espacio le queda a la lectura comprensiva?

Los medios digitales facilitan introducirse en el ámbito de la creación y difusión de un modo radicalmente distinto a las épocas precedentes. No nos limitamos a ser usuarios pasivos, sino que se realizan con aquellas operaciones diversas de producción y reproducción. Es a lo que, en otro lugar, parafraseando una expresión de la antropología, etiquetamos como "bricolaje tecnológico" (San Martín, 2009). Operación 
que modifica el significado original del libro de texto y de los materiales curriculares, y alude a la producción de nuevos sentidos a partir del modo experiencial y operatorio de generar contenidos de utilización en el aula. Explícitamente en el documento de competencias docentes se propone: "Área 3. Creación de contenidos digitales" que se concreta en lo siguiente: "Crear y editar contenidos digitales nuevos, integrar y reelaborar conocimientos y contenidos previos, realizar producciones artísticas..." (VV. AA, 2017, p. 18).

La idea de bricolaje está implícita en esta competencia, con el añadido que el énfasis se pone en el manejo de las herramientas tecnológicas y no tanto en la valía de los significados creados o recreados. Y es que como señala Turkle (1997, p. 79), explorar "la red es un proceso de probar una cosa, después otra, de hacer conexiones, de juntar elementos dispares. Es un ejercicio de bricolaje". Es, en definitiva, un estilo diferente de aproximarse a la cultura tecnológica que suelen calificar los analistas como "blanda" en contraposición a la "dura" del experto, aunque no por ello menos efectiva en cuanto al dominio cognitivo. Así lo planteaba una madre:

Yo creo que son bastante mejores los materiales digitales, son mucho más variados, es posible adaptarlos a los diferentes temas que se trabajan en clase. Veo que la maestra los selecciona entre los muchos a los que tiene acceso, los retoca o los crea nuevos... (EFCS2).

Un profesor con bastante experiencia de trabajo con las tecnologías en sus clases.

Desde luego que ahora hay tareas que se hacen más cómodas con los ordenadores y todo eso, pero la verdad es que, si te preocupas un poco, tienes más trabajo que nunca. Antes cogías el libro y estaba todo ahí. Ahora ponte a buscar datos, vídeos, redacta un texto para montar, con todo, la unidad didáctica. Un trabajo que luego en clase igual te dura una hora, simplemente porque ese día los chicos estaban más activos... (EP8).

Es evidente que, la presencia de estas tecnologías, intensifica el trabajo del profesorado, le exigen que sea experto en didáctica, en la disciplina y en el manejo de los artefactos tecnológicos. Todo a pesar de relegarlo a un papel secundario, de auxiliar que se dedica a acompañar a los estudiantes en su proceso de aprendizaje, a seleccionar contenidos, a animar el trabajo en el aula. Pero esto plantea algunas cuestiones que consideramos especialmente significativas, como ¿quién ocupa el espacio institucional que deja el docente? ¿Tal vez los agentes que comercializan los nuevos contenidos digitales? ¿Si la enseñanza se nutre de estas piezas sueltas de contenido tomado de otros campos, cómo se le dará continuidad al proceso de aprendizaje o garantizará la valía académica de dichas piezas? Recordemos que son precisamente la fragmentación y la accesibilidad en la información lo que nos ha sumergido en la "postverdad".

\section{Consideraciones finales}

Llegados a este punto parece razonable ir sacando alguna consecuencia de todo lo expuesto y apoyado con datos y pensamientos de los agentes escolares. Hemos 
mantenido que el libro de texto correrá una suerte paralela a la del libro, cuya mayor producción, hoy por hoy, se concentra en unos pocos conglomerados empresariales. Desde el punto de vista escolar, la cuestión fundamental no es tanto la transición del libro en papel al electrónico ya sea accesible en dispositivo móvil o en la red. Lo relevante es el paso del libro a los "contenidos digitales", dotados ahora de un formato transmedia y almacenados en la nube o en repositorios como Procomún del INTEF, YouTube o el portal Marea Verde, entre muchísimos otros. En definitiva, lo que está en juego es el modelo de producción y acceso al conocimiento con el que se socializan nuestros estudiantes.

La transición a la que aludimos suscita no pocas controversias, entendidas éstas no tanto como oposición a las innovaciones, sino en cómo articular la participación pública en el filtrado y asimilación de los avances en aplicaciones de tecnologías. Se observa entre los agentes entrevistados que ni la innovación tecnológica ni las formas de uso de los más jóvenes parecen ser cuestionados. Familias y profesorado, más bien, manifiestan desconcierto ante la rápida sustitución de unos artefactos por otros, y la dificultad para seguir y supervisar lo que el alumnado hace con los dispositivos más avanzados. Mientras que las alumnas y alumnos de los últimos cursos de primaria prefieren mayoritariamente los nuevos soportes, tal como nos manifestaron en las entrevistas. El asunto tiene el suficiente calado como para que los agentes escolares discutan y se impliquen en el análisis de la valía cultural y didáctica de los artefactos tecnológicos. Entre otras razones, porque como concluye Viñao (2002), el aprendizaje escolar de la lectura y escritura se encuentra en un "nuevo momento crítico".

La innovación y las pautas de consumo cultural favorecen la presencia en las aulas de las tecnologías más avanzadas, porque todo ello promueve un modelo de conocimiento y de subjetividad distinto al auspiciado por la modernidad. Las impresoras convencionales nos facilitaban el acceso a un relato alfabético, mientras que las actuales impresoras 3-D propician la experiencia de tocar/sentir un objeto. En términos de conocimiento puede ser muy semejante a lo de los auriculares aludidos al principio, en cuanto al aprendizaje y traducción de una lengua extranjera, más proclives a ofrecer una experiencia gratificante que un auténtico aprendizaje.

Tanto los datos más empíricos como las controversias que afloran en el trabajo con los agentes escolares avalan el planteamiento de Ong (1987, p. 150), para quien una nueva tecnología de la palabra refuerza a la vieja, pero al mismo tiempo la transforma. El libro digital y muy especialmente los contenidos digitales proponen un cambio importante en el orden epistémico, pues cambian la relación del sujeto con el relato. Entre otras razones porque el texto impreso potencia la introspección mientras que el texto electrónico, más icónico que alfabético, fomenta la oralidad secundaria entre sus receptores, porque también cambia el espacio de recepción (el libro de texto demanda unos espacios y la tableta otros escenarios).

Definitivamente el debate no debería centrarse tanto en si al libro de texto le espera un futuro más o menos halagüeño ni tampoco si el soporte digital va a acabar con la presencia de los manuales clásicos en las aulas. Éste no es el problema, más bien hemos de concentrar los esfuerzos en reflexionar sobre cómo combinar de modo fructífero ambas tecnologías: la analógica y la digital. El mayor o menor peso de uno u otro 
formato, dependerá de las relaciones de poder entre los agentes económicos del sector que controlan el acceso a los contenidos curriculares y perfilan con mayor peso el modelo de educación a promover desde las aulas.

Presentación del artículo: 20 de diciembre de 2017

Fecha de aprobación: 8 de enero de 2018

Fecha de publicación: 31 de enero de 2018

San Martín Alonso, A., y Peirats Chacón, J. (2018). Controversias en la transición del libro de texto en papel y electrónico a los contenidos digitales. RED. Revista de Educación a Distancia, 56. Consultado el (dd/mm/aaaa) en http://www.um.es/ead/red/56/san_martin_peirats.pdf

\section{Financiación}

Trabajo realizado en el marco del proyecto "La escuela de la sociedad digital: análisis y propuestas para la producción y uso de los contenidos digitales educativos" (Ref. EDU2015-64593-R). Financiado por el Programa Estatal de I+D+i Orientada a los Retos de la Sociedad convocado por el Gobierno de España.

\section{Referencias bibliográficas}

Aibar, E. (2002). El conocimiento científico en las controversias públicas. En E. Aibar, \& M.A. Quintanilla, Cultura tecnológica. Estudios de Ciencia, Tecnología y Sociedad (pp. 105-126). Barcelona: ICE-Horsori.

Anta, J. M. (2017). Los puntos de venta de libros y publicaciones periódicas. En J.A. Millán (Coord.). La lectura en España. Informe 2017. Madrid: FGEE. Recuperado de http://www.fge.es/lalectura/2017/

Apple, M. (1989). Maestros y textos. Madrid: Paidós.

Redacción Boletín Salesiano (2017). Una herramienta para conectar escuelas. Boletín Salesiano, 10 de noviembre de 2017. Recuperado de http://boletinsalesiano.com/?p=16451

Bustamante, E. (2011a). España y Latinoamérica. Economía creativa del entretenimiento digital. En E. Bustamante (Ed.), Industrias creativas. Amenazas sobre la cultura digital (pp. 117- 136). Barcelona: Gedisa.

Bustamante, E. (2011b). Cultura digital: la "nueva cultura clásica. Telos. Cuadernos de Comunicación e Innovación, 88, 59-64. Recuperado de http://ir.uv.es/iQ918cc

Carreras, R. (2017). El mercado de la música en digital. No se trata de transformación digital, sino de transformación cultural. En VV.AA., Anuario AC/E de cultura digital-2017 (pp. 20-46). Madrid: Acción Cultural Española.

Controversias en la transición del libro de texto en papel y electrónico a los contenidos digitales. Ángel San Martín Alonso y José Peirats Chacón. 
Celaya, J. (2016). Nuevos escenarios para la industria editorial. El futuro del libro en la era digital. Telos. Cuadernos de Comunicación e innovación, 104, 1-3.

Chartier, R. (2001). ¿Muerte o transfiguración del lector? Revista de Occidente, 239, 72-86.

Choppin, A. (2002). Les manuels scolaires de langues vivantes de 1789 à nos jours. Langues modernes, 1, 6-14.

Escolano, A. (2009). El manual escolar y la cultura profesional de los docentes. Tendencias pedagógicas, 14, 169-180.

Escudero, J.M. (1983). Investigación sobre medios de enseñanza: revisión y perspectivas actuales. Enseñanza \& Teaching. Revista interuniversitaria de didáctica, 1, 87-120.

FGEE (2017). Comercio interior del libro en España-2016. Recuperado de http://links.uv.es/YvNvrc0

Giménez, E. (Coord.) (2017). La edición académica española. Indicadores y características. Madrid: CSIC. Recuperado de http://links.uv.es/k14hZGt

Goody, J., \& Watt, I. (1996). Las consecuencias de la cultura escrita. En J. Goody (Comp.), Cultura escrita en sociedades tradicionales (pp. 39-82). Barcelona: Gedisa.

Martín Gordillo, M. (Coord.) (2006). Controversias tecnocientíficas. Barcelona: Octaedro.

Martínez Bonafé, J. (2002). Políticas del libro de texto escolar. Madrid: Morata.

Millán, J. A. (2015). Edición y difusión del libro. El profesional de la información, 24(6), 699-703.

Mitchell, W.J. (2017). ¿Qué quieren las imágenes? Vitoria: Sans Soleil Ediciones.

Nudler, O. (2004). Hacia un modelo de cambio conceptual: espacios controversiales y refocalización. Revista de Filosofía, 29(2), 7-19.

Ong, W. J. (1987). Oralidad y escritura. Tecnologías de la palabra. México: FCE.

ONTSI, (2016). Informe anual del sector de los contenidos digitales en España-2016. Madrid: ONTSI. Recuperado de http://links.uv.es/0JS2s08

Palao, I. \& Jiménez, H. (2015). Observatorio de piratería y Hábitos de Consumo de Contenidos Digitales. Recuperado de http://links.uv.es/ic0Krng

Controversias en la transición del libro de texto en papel y electrónico a los contenidos digitales. Ángel San Martín Alonso y José Peirats Chacón. 
Peirats, J., Gallardo, I.M., San Martín, Á., \& Cortés, S. (2015). Los contenidos curriculares digitalizados: Voces y silencios en el ámbito editorial. Educatio Siglo XXI. 33(3), 39-62.

Puelles Benítez, M. (2007). La política escolar del libro de texto en la España contemporánea. Avances en supervisión educativa, 6, 1-18.

Rodríguez, J.; Bruillard, E. \& Horsley, M. (Coords.) (2015). Digital Textbook. What's New? Santiago de Compostela: IARTEM-Servizo de Publicacions USC. Recuperado de http://links.uv.es/y4QexVX.

San Martín, A. (2009). La escuela enredada. Barcelona: Gedisa.

Schiller, H.I. (2010). Internet y la crisis del capitalismo. Le Monde Diplomatique, 171, 18-19.

Stake, R.E. (1998). Investigación con estudio de casos. Madrid: Morata.

Strauss, A. \& Corbien, J. (1998). Basics of Qualitative Research: Grounded Theory Procedures and Techniques. London: Sage.

Turkle, S. (1997). La vida en la pantalla. La construcción de la identidad en la era de Internet. Barcelona: Paidós.

Valls, R. (1998). Los manuales escolares y los materiales curriculares en la Historia. IBER, 17, 69-78.

VV.AA. (2017). Marco común de competencia digital docente. Madrid: INTEF. Recuperado de http://links.uv.es/sF0uFZ2

Varela Mallou, J. (2008). El libro de texto ante la incorporación de las TIC a la enseñanza. Santiago de Compostela: CEDRO-USC.

Vázquez, J. \& Celaya, J. (2017). La “netflixización” de la cultura. Blog de Dosdoce.com. Recuperado de http://links.uv.es/x0Vb0h1

Vercelli, A., Becerra, L. y Bidinost, A. (2016). El caso Google Books: ¿usos justos y/o privilegios de copia? Chasqui. Revista Latinoamericana de Comunicación, 133, pp. 113-128.

Viñao, A. (2002). La enseñanza de la lectura y la escritura: análisis sociohistórico. Anales de documentación, 5, 345-359.

\section{Referencias legislativas}

Ley Orgánica 2/2006, de 3 de mayo, de Educación (BOE, 106 de 4 de mayo de 2006).

Controversias en la transición del libro de texto en papel y electrónico a los contenidos digitales. Ángel San Martín Alonso y José Peirats Chacón. 
Ley Orgánica 10/2007, de 22 de junio, de lectura, del libro y de las bibliotecas (BOE, 150, de 23 de junio de 2007).

Ley Orgánica, 8/2013, de 9 de diciembre, para la mejora de la calidad educativa (BOE, 295 de 10 de diciembre de 2013).

Ley Orgánica 3/2014, de 27 de marzo, por la que se modifica el texto refundido de la Ley General para la Defensa de los Consumidores y Usuarios y otras leyes complementarias, aprobado por el Real Decreto Legislativo 1/2007, de 16 de noviembre (BOE, 76 de 28 de marzo de 2014).

Real Decreto-ley 12/2017, de 3 de julio, por el que se modifica el texto refundido de la Ley de Propiedad Intelectual, aprobado por el Real Decreto Legislativo 1/1996, de 12 de abril, en cuanto al sistema de compensación equitativa por copia privada (BOE, 158 de 4 de julio de 2017).

Real Decreto 1744/1998, de 31 de julio, sobre uso y supervisión de libros de texto y demás material curricular correspondiente a las enseñanzas de Régimen General (BOE, 212 de 4 de septiembre de 1998). 